\title{
EDUCAÇÃO ESCOLAR E MEIO AMBIENTE: uma análise a partir de Estudantes e Professores do Ensino Médio
}

\section{SCHOOL EDUCATION AND THE ENVIRONMENT: an analysis from High School Students and Teachers}

\section{EDUCACIÓN ESCOLAR Y MEDIO AMBIENTE: un análisis de estudiantes y profesores de secundaria}

\author{
Josinaldo Cavalcante ${ }^{1}$
}

1. Sociólogo. Especialista em Desenvolvimento e Meio Ambiente. IFPB - Campus Monteiro-PB.

RESUMO: Entendendo ser a escola um ambiente de socialização, onde os indivíduos são preparados não somente para o mercado de trabalho, mas principalmente para a vida em sociedade, entendendo também a preservação ambiental como algo extremamente importante no sentido de que se possa garantir a sobrevivência da atual e das futuras gerações é que resolvemos realizar este trabalho, com o qual pretendeu- se conhecer a atenção dispensada por docentes e discentes sobre as questões Ambientais. Neste contexto o presente trabalho teve como objetivo investigar a maneira como a questão ambiental é trabalhada em uma instituição de ensino na cidade de Monteiro-PB, Brasil. O estudo em questão tratou-se de uma pesquisa exploratória com abordagem qualitativa e quantitativa com técnica de análise de conteúdo. $\mathrm{O}$ trabalho foi realizado em uma Escola Estadual de Ensino Médio em Monteiro-PB com alunos e com professores de biologia e geografia das turmas do 30 ano "A" e "D" do ensino médio, em uma Escola Estadual da cidade de Monteiro-PB. Neste estudo verificou-se que o entendimento dos educandos sobre o conceito de Meio Ambiente foi frágil, superficial, não condizente com a aprendizagem de alunos do $3^{\circ}$ ano do ensino médio. Portanto, mesmo os alunos tendo acesso à informação e conscientes de seus atos, não estão sensibilizados para pôr em prática o que foi aprendido.

Palavras-chave: Educação Ambiental. Escola Pública. Ensino-Aprendizagem.

\begin{abstract}
Understanding that school is a socialization environment, where individuals are prepared not only for the job market, but mainly for life in society, also understanding environmental preservation as something extremely important in order to guarantee the survival of the current and for future generations, we decided to carry out this work, with which it was intended to know the attention given by teachers and students on Environmental issues. In this context, the present study aimed to investigate the way the environmental issue is dealt with in an educational institution in the city of Monteiro-PB. The study in question was an exploratory research with a qualitative and quantitative approach with content analysis technique. The work was carried out in a State High School in Monteiro-PB with students and with teachers of biology and geography of the classes of the 30 year " $A$ " and " $D$ " of high school, in a State School in the city of Monteiro-PB, Brazil. In this study it was found that the students' understanding of the concept of the Environment was fragile, superficial, not consistent with the learning of students in the 3rd year of high school. Therefore, even though students have access to information and are aware of their actions, they are not sensitized to put into practice what has been learned.
\end{abstract}

Keywords: Environmental Education. Public school. Teaching-Learning.
RESÚMEN: Comprender que la escuela es un entorno de socialización, donde las personas están preparadas no solo para el mercado laboral, sino principalmente para la vida en sociedad, también comprenden la preservación del medio ambiente como algo extremadamente importante para garantizar la supervivencia de la corriente. y para las generaciones futuras, decidimos llevar a cabo este trabajo, con el que se pretendía conocer la atención brindada por docentes y estudiantes sobre temas ambientales. En este contexto, el presente estudio tuvo como objetivo investigar la forma en que se aborda el problema ambiental en una institución educativa en la ciudad de Monteiro-PB. El estudio en cuestión fue una investigación exploratoria con un enfoque cualitativo y cuantitativo con técnica de análisis de contenido. El trabajo se llevó a cabo en una escuela secundaria estatal en Monteiro-PB, Brasil con estudiantes y con profesores de biología y geografía de las clases de 30 años "A" y "D" de la escuela secundaria, en una escuela estatal en la ciudad de Monteiro-PB . En este estudio se encontró que la comprensión de los estudiantes del concepto de Medio Ambiente era frágil, superficial, no consistente con el aprendizaje de los estudiantes en el tercer año de la escuela secundaria. Por lo tanto, a pesar de que los estudiantes tienen acceso a la información y son conscientes de sus acciones, no están sensibilizados para poner en práctica lo aprendido.

Palabras clave: Educación ambiental. Escuela pública. Enseñanza-Aprendizaje. 


\section{Introdução}

Por educação entende-se o momento em que regularmente se estuda na escola, porém ela vai, além disso, podendo ser entendida como um processo o qual vai gradativa e naturalmente construindo a personalidade e o caráter do indivíduo. Neste processo que perdura toda a existência aprende-se valores como o coletivismo, a busca pelo bem comum entre outros.

Na concepção de educação tradicional o educando era visto como uma tabua rasa, sendo tarefa da escola lhe repassar conhecimentos testando por meio de provas se tais conhecimentos haviam sido assimilados ou não. Já para o educador pernambucano Paulo Freire, crítico ferrenho da Educação Tradicional "saber ensinar não é transferir conhecimento, mas criar as possibilidades para a sua própria produção ou a sua construção" (FREIRE, 1996).

Freire (1996), defendia um tipo de educação que considerasse os conhecimentos trazidos pelos discentes, e a partir de tais conhecimentos outros seriam construídos de forma dialógica e não repassados como no modelo do qual era crítico. Segundo o que reza a Lei $n^{\circ} 9.394$ de 20 de dezembro de 1996 compreendem a Educação Básica, a educação infantil, o ensino fundamental e o ensino médio e ainda pela Educação Superior.

O presente trabalho tem por objetivo realizar uma pesquisa com estudantes e professores das turmas do $3^{\circ}$ ano de uma Escola em Monteiro - PB. Buscaremos em tal pesquisa perceber a maneira como as questões ambientais são tradas na escola, nas disciplinas de Biologia, Geografia e Sociologia. Pretendemos também conhecer algumas atitudes que diariamente são praticadas pelos educando e educadores em relação à natureza, seja dentro ou fora da sala de aula e suas consequências no meio ambiente em que vivemos.

Com o intuito de conhecer o pensamento de alguns autores a respeito do referido tema, faremos breve revisão de literatura na qual discorreremos sobre o conceito de meio ambiente, o papel que a educação escolar exerce na formação dos indivíduos, o que venha ser educação ambiental. E qual o seu papel, e por fim abordaremos o conceito de sustentabilidade.

A degradação ambiental com a qual hoje nos deparamos é o resultado de uma relação equivocada e egoísta, que durante muito tempo prevaleceu entre o homem e a natureza. Nesta relação, o meio ambiente era visto pelo ser humano apenas como algo a ser dominado e explorado, esquecendo-se este, de que ele também faz parte da natureza e que ao destrui-la estará se auto destruindo.

Diante de tamanha complexidade que envolve a relação do homem com o meio ambiente, se faz necessário que toda a sociedade civil organizada, principalmente a escola, a qual tem como um 
de seus objetivos, preparar cidadãos para o convívio social, conscientizar os educandos a respeito de tal complexidade.

O esgotamento de alguns recursos naturais e a reação da natureza por meio de tsunamis, enchentes, secas prolongadas e outros fenômenos, tem levado o homem a refletir sobre suas relação com o meio ambiente. Tal postura tem exigido, dos governantes medidas, que visem não somente a proteção ecológica, mas também a conscientização da população no sentido de que os mesmos compreendam que a utilização dos recursos naturais de forma irracional pode levar a destruição do próprio homem.

Desta forma, e entendendo ser a escola um ambiente de socialização, onde os indivíduos são preparados não somente para o mercado de trabalho, mas principalmente para a vida em sociedade, entendendo também a preservação ambiental como algo extremamente importante no sentido de que se possa garantir a sobrevivência da atual e das futuras gerações é que resolvemos realizar este trabalho, com o qual se pretende conhecer a atenção dispensada por docentes e discentes, investigando como a questão ambiental é trabalhada em uma instituição de ensino da cidade de Monteiro-PB, Brasil.

\section{Material e Métodos}

O estudo em questão tratou-se de uma pesquisa exploratória com abordagem qualitativa e quantitativa realizado em uma Escola Estadual de Ensino Médio em Monteiro- PB.

Foram constituídas de alunos e professores de biologia e geografia das turmas do $3^{\circ}$ ano "A" e "D" do ensino médio, em uma Escola Estadual da cidade de Monteiro- PB. Para preservar a identidade dos alunos, os mesmos foram identificados, a critério do Pesquisador por A1, A2, ..., A30. E os professores foram identificados por PB1, PB2, PG1 e PG2.

Para a coleta de dados foi utilizado o questionário, o qual é definido por Haguette (1987) como sendo "um instrumento de pesquisa constituído por uma série de questões sobre determinado tema". Tal questionário foi elaborado com questões, abertas e fechadas.

A aplicação dos questionários, bem como a realização das entrevistas foi efetivada pelo próprio pesquisador junto à amostra. Vale ressaltar que essas ações ocorreram mediante a aceitação expressa no Termo de Consentimento Livre e Esclarecida, que foi elaborado pelo investigador.

Já para a coleta dos dados dos educadores utilizou-se questões abertas e fechadas por meio da aplicação do questionário, o qual conforme, Haguette (1987) pode ser entendido como "um instrumento de pesquisa constituído por uma série de questões sobre determinado tema”, e também entrevistas. 
O processo de coleta de dados ocorreu da seguinte forma: Inicialmente o pesquisador responsável realizou a leitura do questionário e as devidas explicações quanto a seu preenchimento, visto que no questionário contam questões abertas também;

O Termo de Consentimento Livre e Esclarecido foi entregue e assinado previamente pelos alunos participantes da pesquisa. A aplicação dos questionários ocorreu de forma individual na Instituição de Ensino onde os alunos estudam.

A duração de aplicação dos questionários foi de cerca de trinta minutos e durante este período o pesquisador se manterá na sala onde tais questionários serão aplicados. E por último as entrevistas que foram realizadas pelo pesquisador com alunos e professores.

Nesta fase a pesquisa seguiu as etapas propostas por Lefèvre e Lefèvre, detalhadamente: 1 . Organização do material coletado, listagem e leitura dos dados; 2. Releitura dos textos e 3. Identificação dos temas, pertinentes às questões correspondentes; Em seguida, agrupou-se os dados segundo os elementos significativos que se somam ou se confirmam num mesmo plano de significado;

Foram observadas as normas éticas determinadas na resolução $n^{\circ} 466 / 12$ do Conselho Nacional de Saúde, na perspectiva de garantir o anonimato dos participantes, assim como a sua autonomia no que se refere no consentimento livre e esclarecido e respeito à vida, objetivando o exercício pleno da autonomia (BRASIL, 2012). Tendo sido aprovado pelo CEP do IFPB CAAE: 51623615.1 .0000 .5185 .

\section{Resultados e Discussão}

\section{Percepção dos alunos}

De acordo com a metodologia os objetivos foram alcançados e os resultados estão expressos a seguir.

Observa-se que todos os alunos pesquisados são solteiros e com idade entre 15 e 18 anos (Figura 1).

Figura 1. Idade dos pesquisados segundo a disciplina cursada. Monteiro-PB. 2015.

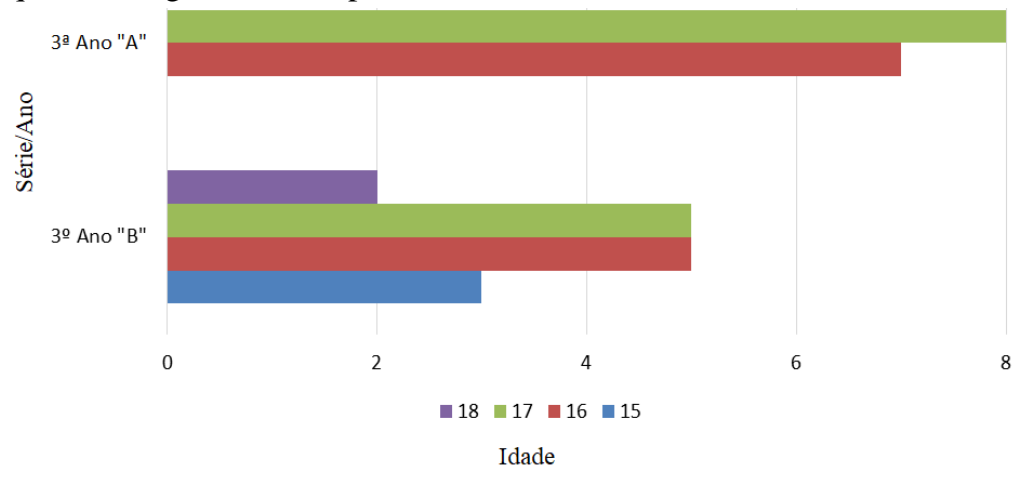


Este estudo diverge do trabalho de Andrade, (2006), que utilizou questionários na escola de ensino fundamental da cidade de Palmas-TO, a pesquisa foi realizada com 41 alunos de faixa etária de 08 a 12 anos, para avaliar o nível de consciência ambiental dos alunos.

No que diz respeito ao gênero dos alunos pesquisados, a maioria era do gênero feminino (Figura 2).

Figura 2. Gênero dos pesquisados segundo a disciplina cursada. Monteiro-PB. 2015.

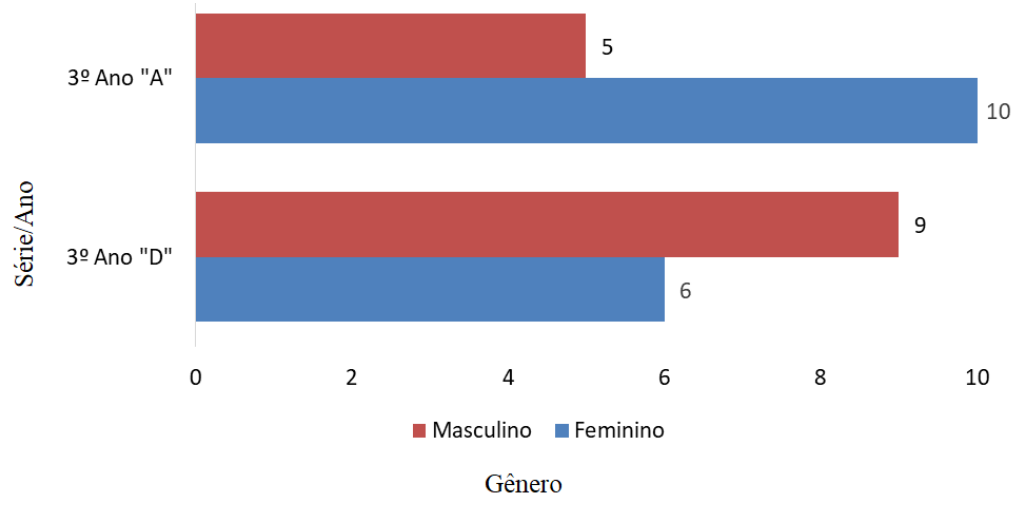

Estes dados corroboram com a pesquisa de Silva et al. (2009), que fez um diagnóstico dos alunos de ensino médio sobre Educação Ambiental em no município de Palmas-TO, e verificou que no total de 104 alunos que responderam o questionário $100 \%$ são solteiros, 99\% tem sua faixa etária com menos de 20 anos de idade, sendo que $61 \%$ são do gênero feminino e $39 \%$ do masculino.

No que se refere à ocupação laboral, verificou-se que apenas 16,67\% exercem alguma função (Figura 3), sendo que, dentre os alunos da turma do $3^{\circ}$ ano "A", um trabalha 3 horas/dia numa padaria e o outro, 7 horas/dia, numa empresa de hortifrutigranjeiro. Já, dentre os do $3^{\circ}$ ano "D", dos 3 que exercem alguma atividade laboral, apenas declarou que trabalha na UEPB (Universidade Estadual da Paraíba) pelo período 9horas/dia.

Figura 3. Ocupação laboral dos pesquisados segundo a disciplina cursada. Monteiro-PB. 2015.

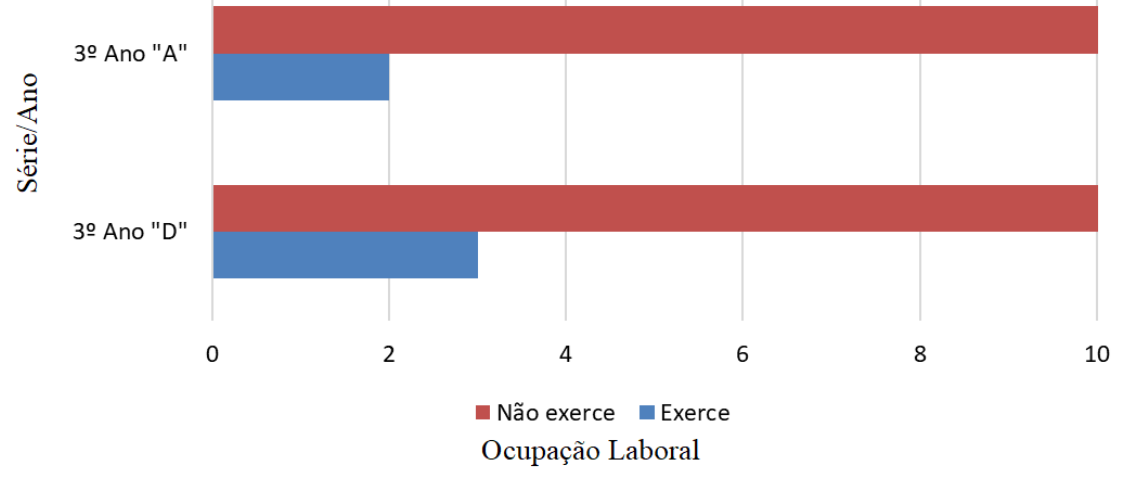


Quanto à residência, a maioria dos pesquisados residem na zona urbana (Figura 4).

Figura 4. Zona de residência dos pesquisados segundo a disciplina cursada. Monteiro-PB. 2015.

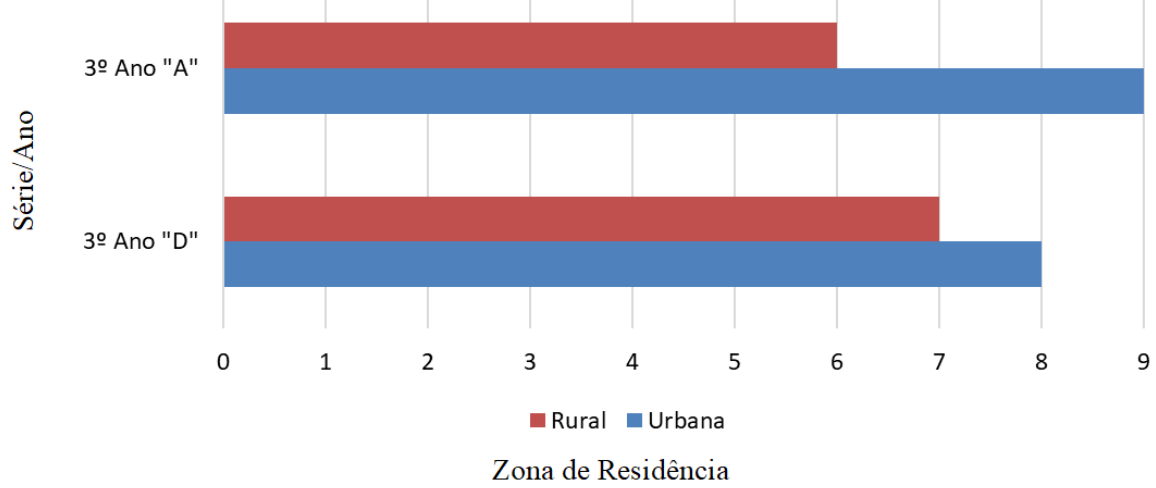

Comparando nossos dados com os estudos de Lopes et al. (2011) para o município de Araras-SP, o resultado segue uma tendência inversa, pois ele estudou cerca de 300 crianças, das quais aproximadamente $80 \%$ moram na zona rural do município.

Quando os alunos foram perguntados sobre o conceito de Meio Ambiente, pode- se perceber que as respostas são vazias, simplórias e que não refletem o conceito que é, inclusive, trabalhado nos livros didáticos do Ensino Fundamental e Médio (Quadro 1).

Evidencia-se com esses resultados, que a simplicidade dos conceitos aqui expressos, podem estar relacionados à forma como as aulas e os conteúdos são abordados em sala de aula e/ou relacionados a cultura do local estudado.

Quadro 1. Conceito dos pesquisados sobre Meio Ambiente. Monteiro-PB. 2015.

\begin{tabular}{|c|c|}
\hline Alunos & Conceito \\
\hline $\mathrm{A} 1, \mathrm{~A} 27$ & É o espaço onde há vida. \\
\hline $\mathrm{A} 2$ & É onde nós moramos. \\
\hline $\mathrm{A} 3, \mathrm{~A} 5, \quad \mathrm{~A} 12, \mathrm{~A} 13, \mathrm{~A} 15$ & É onde a gente vive é a natureza. \\
\hline $\mathrm{A} 4, \mathrm{~A} 22, \mathrm{~A} 25, \mathrm{~A} 26$ & É uma coisa que precisamos preservar bastante \\
\hline A6 & É onde se encontra vida em nosso planeta. \\
\hline A7 & É um ambiente que deve ser tratado com amor e faz parte de nossas vidas. \\
\hline $\mathrm{A} 8, \mathrm{~A} 14$ & É onde as pessoas vivem, lugar habitável. \\
\hline A9, A17, A19 & É o local onde vivemos e interagimos com a natureza. \\
\hline $\mathrm{A} 10, \mathrm{~A} 21$ & É tudo que existe em nosso planeta. \\
\hline A11 & É a natureza, as árvores, ou seja, tudo aquilo que o homem não consegue produzir. \\
\hline A16 & É tudo que nós vemos. \\
\hline $\mathrm{A} 18$ & É a natureza e tudo que existe de espaço na Terra. \\
\hline $\mathrm{A} 20, \mathrm{~A} 23, \mathrm{~A} 24$ & É a valorização da natureza. \\
\hline A28 & $\begin{array}{c}\text { É o espaço geográfico natural onde nós deparamos com uma natureza, onde devemos } \\
\text { respeitar e preservar. }\end{array}$ \\
\hline
\end{tabular}




\begin{tabular}{|c|c|}
\hline A29 & É a coisa mais linda que Deus criou. \\
\hline A30 & É o local designado para que cada ser humano conviva. \\
\hline
\end{tabular}

Neste contexto, cursos de formação continuada para os professores, além de um Planejamento associado ao Projeto Político Pedagógica da Escola poderão contribuir para uma melhor conceituação do Termo Meio Ambiente e para um melhor desenvolvimento da Educação Ambiental na prática junto às escolas.

Sobre a percepção dos pesquisados o quanto a influência das discussões sobre o Meio Ambiente nas disciplinas cursadas ao longo do ano letivo dos $3^{\circ}$ anos e de que forma isso acontece (Figura 5), pode-se detectar que apenas $10 \%$ afirmaram não ter influenciado em nada.

Figura 5. Percepção dos pesquisados sobre a influência das discussões sobre Meio Ambiente nas disciplinas cursadas. Monteiro-PB. 2015.

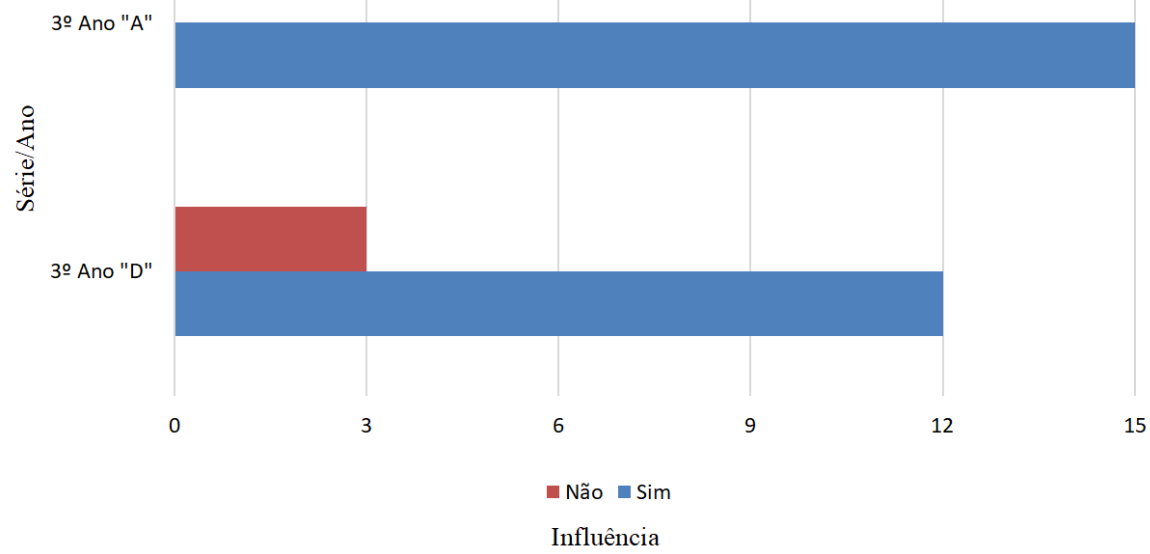

Justificando as questões anteriores e verificando a percepção dos pesquisados, os alunos A18, A22 e A24 disseram "não". Sendo que apenas o A22 justificou, dizendo que "não estava estudando este assunto" (Quadro 2).

Quadro 2. Justificativa da percepção dos pesquisados sobre a influência das discussões sobre Meio Ambiente nas disciplinas cursadas. Monteiro-PB. 2015.

\begin{tabular}{|c|c|}
\hline Alunos & Justificativa \\
\hline $\mathrm{A} 1, \mathrm{~A} 8, \mathrm{~A} 13$ & Acrescenta o conhecimento das outras disciplinas. \\
\hline $\mathrm{A} 2, \mathrm{~A} 9, \mathrm{~A} 28$ & Porque aumenta a discussão da Educação Ambiental. \\
\hline $\begin{array}{l}\text { A3, A4, A5, A7, A10, A11, } \\
\text { A12, A14, A19, A20, A25, } \\
\text { A15 }\end{array}$ & Nos ajuda a conhecer mais a natureza. \\
\hline A6, A26, A27, & Pois aborda mais o assunto. \\
\hline A16 & Nos ajudam a sermos mais ecológicos e reflexivos. \\
\hline A17 & $\begin{array}{l}\text { Só ajuda no Ensino Fundamental, pois no Ensino Médio são outros } \\
\text { assuntos. }\end{array}$ \\
\hline $\mathrm{A} 21, \mathrm{~A} 23, \mathrm{~A} 29, \mathrm{~A} 30$ & Ajuda a compreender o meio ambiente e solucionar vários problemas. \\
\hline
\end{tabular}


Mesmo a maioria dos pesquisados terem afirmado que as discussões sobre a temática Meio Ambiente influenciar na construção do conhecimento escolar junto as demais disciplinas, verifica-se que as justificativas são frágeis conceitualmente estando aquém do que se espera de alunos concluintes do ensino médio.

Ao serem questionados sobre já terem executados ações e atos prejudiciais ao meio ambiente e ao convívio social, verificou-se uma discrepância quanto às condutas entre os dois grupos (Figura 6). Os alunos do $3^{\circ}$ Ano "A" $(66,67 \%)$ deixam as torneiras abertas ao escovar os dentes e/ou lavar as mãos e descartam lixo ao chão; já, 66,67\% dos alunos do $3^{\circ}$ Ano "D", também jogam lixo no chão e $33,33 \%$ deixam torneiras abertas.

Figura 6. Ações degradantes ao Meio Ambiente já executadas pelos dos pesquisados. Monteiro-PB. 2015.

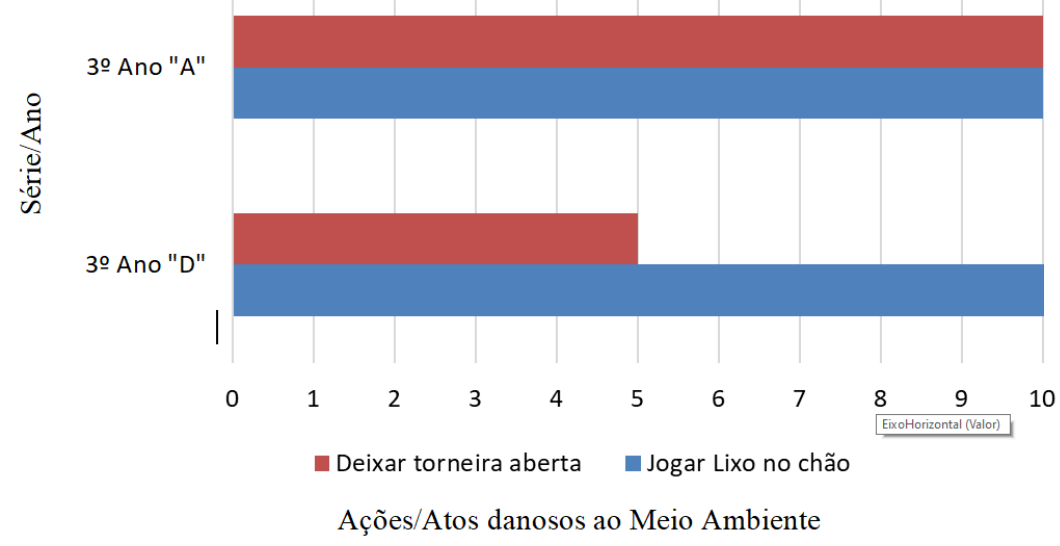

Esses dados refletem e reforçam a condição da educação ambiental e formal ser um “processo contínuo", “social”, “cultural” e "familiar”. Não basta apenas ter acesso a informação. Faz-se necessário que o meio ao quais os alunos estejam inseridos faça uso das informações para que eles possam se tornam cidadãos aptos a executarem tudo que foi trabalhado em sala de aula.

Pois apesar de estarem com acesso a informação e conscientes de seus atos, não estão sensibilizados para porem em prática o que foi aprendido.

\section{Diagnóstico dos Professores}

Para que se pudesse perceber a maneira em que a temática ambiental fosse trabalhada na cidade de Monteiro-PB, optou-se por aplicar um questionário aos professores de biologia e geografia da escola pesquisada, avaliando suas falas conforme os quadros a seguir.

Inicialmente, indagou-se sobre como é trabalhado as questões ambientais nas aulas em suas respectivas turmas (Quadro 3). 
Verifica-se que as aulas sobre as questões ambientais são dinâmicas, atuais, práticas e questionadoras. Porém, o que foi dito pelos professores não condizem com as respostas dos alunos que se expressaram de forma simplória e superficial.

Quadro 3. Como o (a) Sr. (Sra.) costuma trabalhar as questões ambientais em suas aulas?

\begin{tabular}{|c|c|}
\hline Professor(a) & Respostas \\
\hline $\mathrm{P} 1 \mathrm{~B}$ & De forma dinâmica e prática. \\
\hline $\mathrm{P} 2 \mathrm{~B}$ & Em forma de projetos. \\
\hline $\mathrm{P} 1 \mathrm{G}$ & $\begin{array}{c}\text { Primeiro, faço uma pesquisa sobre as questões ambientais existentes a nível de mundo, } \\
\text { depois a nível de Brasil e também a nível de município. }\end{array}$ \\
\hline $\mathrm{P} 2 \mathrm{G}$ & É assim, através de slides, levar para o laboratório de informática. \\
\hline
\end{tabular}

Sobre a metodologia utilizada para trabalhar as questões (Quadro 4), percebe-se nas falas dos professores que a resposta atende aos requisitos e planejamentos atuais. Muito embora, quando se compara com as falas dos alunos, pode-se verificar também que aprece que existe algo de errado ou contraditório, tendo em vista que os alunos parecem não dominar ou não compreender os conceitos trabalhados e expressados pelos professores pesquisados, aparentando um distanciamento entre a teoria e a prática.

Quadro 4. Qual a metodologia utilizada para trabalhar tais questões?

\begin{tabular}{|c|c|}
\hline Professor(a) & Respostas \\
\hline $\mathrm{P} 1 \mathrm{~B}$ & Pesquisas na internet, vídeos das redes sociais, debates e palestras. \\
\hline $\mathrm{P} 2 \mathrm{~B}$ & $\begin{array}{c}\text { Conversas, palestras usando a linguagem dos alunos, duas aulas por mês trato das questões } \\
\text { ambientais. }\end{array}$ \\
\hline $\mathrm{P} 1 \mathrm{G}$ & $\begin{array}{l}\text { Primeiro eles fazem a pesquisa e depois pode apresentar por meio de seminário ou mesmo } \\
\text { escrevendo texto no caderno detectando problemas e apontando soluções dos problemas. }\end{array}$ \\
\hline $\mathrm{P} 2 \mathrm{G}$ & Nós temos o livro didático, a gente trabalha com aquelas questões do ENEM. \\
\hline
\end{tabular}

Quando questionados sobre a receptividade por parte dos educandos em relação as questões ambientais trabalhadas na disciplina, destaca-se a fala do Professor P2G que aborda as dificuldades de se lecionar na atualidade e tornar as aulas mais atrativas e reflexivas.

Sobre as falas dos professores P1B, P2B e P1G, verifica-se a mesma tendência das questões anteriores, pois o interesse, participação e receptividades dos alunos não são expressos nas falas deles.

Quadro 5. Como você avalia a receptividade por parte dos educandos em relação as questões ambientais trabalhadas na disciplina?

\begin{tabular}{|c|c|}
\hline Professor(a) & Respostas \\
\hline $\mathrm{P} 1 \mathrm{~B}$ & Percebo um grande interesse pelos assuntos ambientais. \\
\hline $\mathrm{P} 2 \mathrm{~B}$ & No início há recusa, mas depois eles participam. \\
\hline $\mathrm{P} 1 \mathrm{G}$ & A receptividade é boa, porque eles estão sempre vendo na internet, nos problemas ambientais. \\
\hline
\end{tabular}




\section{P2G}

É assim, hoje em dia os alunos têm uma diferença dos alunos de antigamente, a gente tem que ficar no pé, buscando, puxando, mostrando, por que se não for não vai.

Sobre a necessidade de se ter uma disciplina exclusiva sobre o meio ambiente ou pode ser tratado de forma interdisciplinar, todos concordam que não deve ser uma disciplina especifica, e sim, tratada transversalmente (Quadro 6).

Cabe ressaltar que mesmo todos tendo a pratica de atuar de forma interdisciplinar, percebese que existe uma deficiência quanto a receptividade e sensibilização por parte dos alunos. Dessa forma, a escola e os seus profissionais, devem discutir, planejar e reavaliar as práticas a fim de reduzir as deficiências encontradas neste estudo.

Quadro 6. O(a) Sr.(Sra) acredita haver a necessidade de se ter uma disciplina exclusiva sobre o meio ambiente ou pode ser tratado de forma interdisciplinar?

\begin{tabular}{|c|c|}
\hline Professor(a) & Respostas \\
\hline P1B & $\begin{array}{c}\text { Seria interessante, mais não vejo problema em trabalhar esse assunto de forma } \\
\text { interdisciplinar. }\end{array}$ \\
\hline $\mathrm{P} 2 \mathrm{~B}$ & Não há necessidades. \\
\hline $\mathrm{P} 1 \mathrm{G}$ & $\begin{array}{l}\text { Eu acho que de forma transversal se todo mundo trabalhar bem, eu creio que não há } \\
\text { necessidade não. }\end{array}$ \\
\hline $\mathrm{P} 2 \mathrm{G}$ & É importante ser trabalhada de forma interdisciplinar. \\
\hline
\end{tabular}

\section{Conclusões}

Pode-se perceber que o entendimento dos educandos sobre o conceito de Meio Ambiente foi frágil, superficial, não condizente com a aprendizagem de alunos do $3^{\circ}$ ano do ensino médio.

Em relação às falas dos professores sobre a maneira a qual atuam na formação dos discentes, verificou-se que a maioria apresenta na teoria maneiras atuais e contextualizadas, muito embora, isto não tenha sido confirmada nas falas dos alunos. Ao mesmo tempo que, percebeu-se que a maioria parece desconhecer a fragilidade do ensino-aprendizagem no que diz respeito a temática Meio Ambiente.

Mesmo os alunos tendo acesso a informação e conscientes de seus atos, não estão sensibilizados para porem em prática o que foi aprendido, visto que todos já praticaram ou praticam ações e atos prejudiciais ao meio ambiente e ao convívio social, como jogar lixo no chão e/ou deixar a torneira aberta ao lavar as mãos.

\section{Referências}

ANDRADE, D. F. Implementação da Educação Ambiental em escolas: uma reflexão. In: Fundação Universidade Federal do Rio Grande. Revista Eletrônica do Mestrado em Educação Ambiental, v. 4, 2006. 
BRASIL. Parâmetros Curriculares Nacional: temas transversais. Brasília: MEC, 1996.

BRASIL. Conselho Nacional de Educação (CNE). Resolução n. 3, de 26 de junho de 1998. Institui as Diretrizes Curriculares Nacionais para o Ensino Médio. Diário Oficial da República Federativa do Brasil, Brasília, DF, 5 ago. 1998a.

BRASIL. Conselho Nacional de Educação (CNE). Parecer n. 15, de 1 de junho de 1998. Diretrizes Curriculares Nacionais para o Ensino Médio. Brasília, DF, 1998b.

BRASIL. Lei 9795 que dispõe sobre a educação ambiental. Brasília-DF: DOU, 27/04/1999.

BRASIL. Ministério da Educação. Orientações curriculares do ensino médio. Brasília, DF, 2000.

BRASIL. Ministério da Educação e cultura. Parâmetros Curriculares Nacional, disponível em:<http://portal.mec.gov.br/index.php>. Acesso em: 10 dez. 2015

CARVAlHO, I. C. M. Educação Ambiental: Formação do Sujeito Ecológico. São Paulo. Cortez. 2008.

DIAS, G. F. Educação Ambiental: Princípios e Práticas. 5. ed. São Paulo; Gaia, 2003.

DURKHEIM, E. Educação e sociologia. 7. ed. São Paulo: Melhoramentos, 1978.

FAZENDA, I. C. A. Interdisciplinaridade: história, teoria e pesquisa. 14. ed. Campinas: Papirus, 2007.

FREIRE, P. Pedagogia da Autonomia: saberes necessários à prática educativa.

São Paulo: Paz e Terra, 1996.

FREIRE, P. Pedagogia da autonomia: saberes necessários à prática educativa. 30 . Ed. São

Paulo: Paz e Terra, (Coleção Leitura). 1996.

GADOTTI, M. Perspectivas atuais da educação. Porto Alegre, Ed. Artes Médicas, 2000.

GUIMARÃES, M. A. Dimensão Ambiental Na Educação. Campinas, SP: Papirus, 1995 (Coleção Magistério: formação e trabalho pedagógico. 1995. 107 p.

HAGUETTE, T. M. F. Metodologias qualitativas na Sociologia. 3. ed.Petrópolis: Vozes, 2001.

KUENZER, A. Z. (Org.). Ensino Médio: construindo uma proposta para os que vivem do trabalho. São Paulo: Cortez, 2005.

LEFEVRE, F.; LEFEVRE, A. M. C. O discurso do sujeito coletivo: um novo enfoque em pesquisa qualitativa. Caxias do Sul: Educs, 2003.

LEFF, E. Educação ambiental e desenvolvimento sustentável. In.: REIGOTA, Marcos (org.). Verde cotidiano: o meio ambiente em discussão. DP\&A. Rio de Janeiro: p.111- 129, 1999.

LIBÂNEO, J. C. Organização e gestão da escola: teoria e prática. 5. ed. revisada e ampliada. Goiânia-GO: Alternativa, 2004.

LOPES, P. R. et al. Diagnóstico socioambiental: o meio ambiente percebido por estudantes de uma escola rural de Araras (SP). Pesquisa em Educação Ambiental, [S.1.], v. 6, n. 1, p. 139-155, july. 2012.

MORIN, E. A cabeça bem-feita: repensar a reforma, reformar o pensamento. Trad.: Eloá Jacobina. 7a ed. Rio de Janeiro: Bertrand Brasil, 2002. 
MOREIRA, A. F. Ambientes de Aprendizagem no Ensino de Ciência e Tecnologia.

Belo Horizonte: CEFET-MG, Notas de aula, 2007.

MORENO, M. Temas Transversais: um ensino voltado para o futuro. 4. Ed. SP: Ática, 2000.

OLIVA, J. M. El Pensamiento Analógico desde la Investigación Educativa y desde la Perspectiva del Profesor de Ciências. Revista Electrónica de Enseñanza de las Ciencias, v. 3, n.3. 2005.

PEDRINI, A. G. Educação Ambiental: reflexões e práticas contemporâneas. 5. ed. ed. Petrópolis Vozes, 1997.

PILETTI, C. Filosofia da educação. São Paulo: Ática,1998.

REIGOTA, M. A. S. Ciência e Sustentabilidade: a contribuição da educação ambiental. Avaliação (Campinas), v. 12, jun., 2007.

SEGURA, D.S.B. Educação ambiental na escola pública: da curiosidade ingênua a consciência crítica. São Paulo. Annablume, 2001.

SILVA, R. C. R. et al. Nível de atividade física em adolescentes do Município de Niterói, Rio de Janeiro, Brasil. Cadernos de Saúde Pública, Rio de Janeiro, v. 16, n. 4, p. 1091-1097, 2009.

SOUSA, P. R. PCN Ensino Médio. 1999.

VASCONCELlOS, H. S. R. A pesquisa-ação em projetos de Educação Ambiental. Petrópolis, Vozes, 1997. 